\title{
Effect of topical phenytoin on wound healing
}

\author{
Ranendra Hajong, Narang Naku, Debobratta Hajong, Madhur Anand, K Lenish \\ Singh, Nilanjan Majumdar \\ Department of General surgery, NEIGRIHMS, Shillong
}

\begin{abstract}
:
Aim of the study: To study the effect of topical phenytoin in healing of grade I and II diabetic foot ulcers. Background: Diabetic foot ulcers entail a lot of financial burden both to the patients and also to the treating hospitals. These are estimated to affect $15 \%$ of all diabetic individuals during their lifetime. These precede almost $85 \%$ of amputations. In India, prevalence of diabetic foot ulcer in clinical population is 3.61\%. Increase in the prevalence of foot complications in India is attributed to socio-cultural practices such as bare foot walking, religious practices like walking on fire, use of improper foot wear and lack of knowledge regarding foot care. The three etiological mechanisms involved in formation of diabetic foot ulcer are- ischemia, neuropathy and infection.Phenytoin has been used by some workers and the possible mechanisms of its action in ulcer healing have been described as-increase in the proliferation of fibroblasts, increase in the deposition of collagen, neovascularisation, enhanced granulation tissue formation, decrease in the action of collagenase, decrease in bacterial contamination by removing Staphylococcus aureus, Escherichia coli, Klebsiella species, and Pseudomonas from the wound.

Material and methods: A total of one hundred patients (66 males and 34 females) were enrolled in the study half of which were dressed with crushed phenytoin tablet powder (Group 1) and the remaining half was dressed with normal saline (Group 2). Statistical analysis was done using using the SPSS version 22 for Windows, Inc Chicago II.Descriptive statistics was used to find the mean \pm standard deviation.Mann Whitney test was done to find the difference between the various variables in the two groups.

Results: Phenytoin was found to help in early healing of diabetic foot ulcers with the mean epithelisation time was found to be significantly lower in the phenytoin group.

Conclusion: Topical phenytoin enhances healing of diabetic foot ulcers and is a cheap and effective modality of treating these patients.
\end{abstract}

Keywords: Diabetic ulcer; wound healing; phenytoin tablets; topical application.

\section{Introduction}

Wound healing is the process of restoration of physical integrity of internal or external body structures and involves complex interactions between the cells and various other factors ${ }^{1}$. Appropriate treatment and wound care accelerate the healing process and prevent infection and chronicity of the wound ${ }^{2}$. Despite extensive efforts to improve wound healing, the outcomes of existing methods are far from optimal ${ }^{1}$. Diabetic foot ulceration is estimated to occur in $5-10 \%$ of diabetic population ${ }^{3}$. Wound healing may be delayed due to abnormal cell function, hyperglycemia, peripheral neuropathy, peripheral vascular disease, susceptibility to infections and abnormal planter foot pressures, resulting in prolonged morbidity and even loss of part or whole of the foot ${ }^{4}$.

The 5-5dipenyl 2-4 imidazolidione sodium, with generic name of Phenytoin, was synthesized in 1908 and is in clinical use as a potent anti-epileptic drug since $1937^{5}$. A frequently observed and unwanted side effect of phenytoin is gingival hyperplasia, especially in children ${ }^{6}$. In 1939 , Kimball et al first observed that gingival hyperplasia occurred in some patients treated with phenytoin. This stimulated the study regarding the potential use of phenytoin in wound healing ${ }^{7}$.

There are studies and case reports about the use of topical phenytoin for a wide variety of soft tissue infections and ulcers ${ }^{8}$. This study was designed to determine the efficacy of topical phenytoin in the treatment of diabetic foot ulcers as topical use of phenytoin is not in routine use and different studies have shown conflicting results due to methodological flaws, such as inappropriate statistical analysis, inadequate control groups, and the absence of randomization and double-blinding ${ }^{8}$.

\section{Material and methods}

A total of one hundred patients with diabetic foot ulcers grade I and II were enrolled for the study after obtaining due clearance from the Institute Ethics Committee. Written informed consent was taken from every patient with adherence to the Principles of the Declaration of Helsinki. In group 1 fifty patients were dressed using crushed phenytoin tabletsmixed with normal saline and in group 2 fifty patients were dressed with normal 
saline. Patients were randomly allocated to a particular group by using computer generated random numbers. Sample size was calculated by using WHO calculator, level of significance was $5 \%$ and power of test was 95\%.Surgical debridement was done in both groups of patients as and when required. Pus culture was obtained and appropriate antibiotics were used as and when indicated. Ulcer size was measured by tracing the outline on a butter paper and transferred on graph paper and then taking the maximum diameter in two different areas perpendicular to each other. Wound healing was measured on Days 4, 8, 12, 16 and so on. Percentage of wound contracture was found by using the Walker formula ${ }^{9}$ which is percentage of wound area $=$ wound area on day $\mathrm{x}$ /wound area on day1 X 100. Percentage of wound healing= $100-$ percentage of wound area.

Dosage of phenytoin used was as given below:

Size of ulcer in millimetre square - Dosage of phenytoin tablet in milligram
$0-25$
$-100$
$>25-<50$
$-150$
$>50-<75$
$-200$

Efficacy was measured in terms of $50 \%$ or more reduction in area of the ulcer and also the mean epithelisation time in days. Statistical analysis was done using the SPSS version 22 for Windows, Inc Chicago II.Descriptive statistics was used to find the mean \pm standard deviation.Mann Whitney test was done to find the difference between the various variables in the two groups.

Patients with history of hepatic and renal disease, those on steroid use and those with impalpable dorsalis pedis or posterior tibial arteries were excluded.

\section{Results}

Patient profile is shown in Table 1. There was significant difference in the rate of healing between the two groups ( $\mathrm{P}$ value $<0.05)$ with the patients in group 1 healing much earlier than those in group 2 as shown in table 2. Pearson correlation was found between the two groups and group 1 showed significant difference $(\mathrm{P}<0.05)$ than group 2. There was no significant difference in the rate of healing depending on the grade of ulcer as shown in table 3 . Table 4 showed significant difference $(\mathrm{P}<0.05)$ in the rate of $50 \%$ wound contracture in the size of the ulcers.

Table 1 Profile of patients.

\begin{tabular}{|c|c|c|c|c|}
\hline & Number & \% & Mean age & P value \\
\hline Males & 66 & 66 & $57.15 \pm 8.59$ & $\mathrm{P}>0.05$ \\
\hline Females & 34 & 34 & $56.06 \pm 6.70$ & \\
\hline
\end{tabular}

Table 2. Epithelialisation time (days) in two groups

\begin{tabular}{|c|c|c|c|c|}
\hline & Number & $\begin{array}{c}\text { Mean epithelialization } \\
\text { time in days }\end{array}$ & $\begin{array}{c}\text { Standard } \\
\text { Deviation }\end{array}$ & P value \\
\hline Group 1 & 50 & 17.36 & 2.20 & \multirow{2}{*}{$\mathrm{P}<0.05$} \\
\hline Group 2 & 50 & 26.16 & 3.39 & \\
\hline
\end{tabular}

Table 3 Mean Epithelialization time by Grade of Ulcer

\begin{tabular}{|c|c|c|c|c|}
\hline & Number & $\begin{array}{c}\text { Mean Epithelialization } \\
\text { time in days }\end{array}$ & Std Dev. & P value \\
\hline Grade 1 & 82 & 22.02 & 5.31 & \multirow{2}{*}{$\mathrm{P}>0.05$} \\
\hline Grade 2 & 18 & 20.56 & 5.18 & \\
\hline
\end{tabular}

Table 4. 50\% wound contracture in two groups in days

\begin{tabular}{|c|c|c|c|c|}
\hline & Number & $\begin{array}{c}\mathbf{5 0 \%} \text { wound contracture } \\
\text { in days }\end{array}$ & $\begin{array}{c}\text { Standard } \\
\text { Deviation }\end{array}$ & P value \\
\hline Group 1 & 50 & 13.46 & 2.32 & \multirow{2}{*}{$\mathrm{P}<0.05$} \\
\hline Group 2 & 50 & 23.16 & 3.95 & \\
\hline
\end{tabular}

\section{Discussion}

Shapiro carried out the first clinical trial in 1958 and found out that periodontal patients with surgical wounds who were pre-treated with oral phenytoin had less inflammation, less pain, and accelerated healing as compared to controls ${ }^{10}$. Its wound healing promoting effect has been attributed to many mechanisms including increasing fibroblast proliferation, inhibiting collagenase activity, promoting collagen deposition, enhancing granulation tissue formation, decreasing bacterial contamination, reducing wound exudates formation and up regulating growth factor receptors ${ }^{11}$. Biopsies of Phenytoin treated wounds show neovascularization, collagenization and decreased polymorphnuclear and eosinophil cell infiltration ${ }^{12}$. 
Topical application of phenytoin results in direct access of the drug to the target site and avoids the risk of getting systemic side effects ${ }^{13}$. The beneficial effect of phenytoin has also been shown in promoting healing of decubitus ulcers ${ }^{14}$, venous stasis ulcers ${ }^{15}$, traumatic wounds ${ }^{16}$, burns ${ }^{17}$, and leprosy trophic ulcers ${ }^{18}$.

Crushed phenytoin tablet was used for topical application as was done by Rhodes et $\mathrm{al}^{19}$ in their study.

Only patients with grades I and II were included in the study to deal with problems of wounds with undermined margins and alsoarea measurements in deeper wounds is fallacious as they start the healing process from the base of the woundby building up granulation tissue.

Shaw et $\mathrm{al}^{3}$ in 2007 in their meta-analysis of 14 trials of phenytoin on wound healing, found positive percentage treatment effect in favor of the phenytoin-treated group in one study investigating diabetic foot wounds and one study on chronic wounds but there was limited evidence for the use of phenytoin in burns and war wounds. Muthukumarasamy et $\mathrm{al}^{20}$ demonstrated ulcers treated with topical phenytoin healed more rapidly with mean time to complete healing was 21 days as against 45 days in the control $(\mathrm{p}<0.05)$. Similar results were reported by Tauro et $\mathrm{al}^{21}$ where wound area reduction and bacterial clearance was greater in the phenytoin group than in controls. El-Nahas et $\mathrm{al}^{22}$ demonstrated that topical phenytoin significantly improved healing of recalcitrant neuropathic diabetic foot ulcers. Carneiro et $\mathrm{al}^{23}$ also reported significant reduction in pain, clearance of ulcer discharge, early formation of healthy granulation tissue with phenytoin dressing while comparing to EUSOL dressing $(p<0.05)$, however bacterial colonization clearance was not statistically different between the two groups.

Even with all the positive data available, the role of topical phenytoin in the wound healing process is still controversial and efficacy is doubted due to the lack of multicentric, double blind nature of the earlier studies $^{24}$.

Shaw $\mathbf{J}$ et al in their studies concluded that there was nosignificant difference in ulcer closure rates between those with phenytoin dressing and control dressing and hence did not support the use of topical phenytoin in the treatment of diabetic foot ulcers ${ }^{25}$.

Pai et $\mathrm{al}^{26}$ also demonstrated no significant difference in the mean percentage reduction of ulcer area in the phenytoin vs. control group $(78.3 \%$ vs. $73.5 \%$ with $\mathrm{P}>0.05)$ in their double blind controlled trial on the effectiveness of phenytoin in diabetic neuropathic ulcers,

Our study showed marked shortening in the mean epithelisation time and also hastened the rate of ulcer contraction after applying crushed phenytoin tablets to the ulcers. However further research is required to establish phenytoin as healing agent ${ }^{22,26}$.

Conclusion: Topical application of phenytoin in the powder form definitely helps in early healing of diabetic foot ulcers which is cheap and readily available.

\section{References}

[1]. Alizadeh A, Mohagheghi M, Khaneki M, Saeed PK. A study of the effect of magnesium hydroxide on the wound healing process in rats. Med J Islamic World Acad Sci. 2007;16: 165-70.

[2]. Anstead GM, Hart LM, Sunahara JF, Liter ME. Phenytoin in wound healing. Ann Pharmacother. 1996; 30: 768-75.

[3]. Shaw J, Hughes CM, Lagan KM, Bell PM, Stevenson MR. The clinical effect of topical Phenytoin on wound healing: a systematic review. Br J Dermatol 2007;157:997-1004.

[4]. Anis Ahmed, Malik Irfan Ahmed. A comparison of efficacy of topical use of phenytoin and vaseline gauze dressing with vaseline gauze dressing alone in healing of diabetic foot ulcers. J Postgrad Med Inst 2014; 28(3): 297-302.

[5]. Pereira C, Alchome de A. Assessment of the effect of Phenytoin on cutaneous healing from excision of melanocytic Nevi on the face and on the back. BMC Dermatol 2010;10:7.

[6]. McEvoy GK. AHFS drug information 2009. Bethesda, MD: American Society of Health-System Pharmacists; 2009.

[7]. Kimball OP, Horan TN. The use of Dilantin in the treatment of epilepsy. Ann Intern Med. 1939;13:787-93.

[8]. Thompson S, Mary N, Fredrick G. Topical Phenytoin ointment for surgical wounds. Ann Pharmacol. 1994;24:552-4.

[9]. Jarrahi M, Vafaei A. Topical phenytoin cream on linear incisional wound healing in albino rats. DARU. $2004 ; 2: 223-7$.

[10]. Shapiro M. Acceleration of gingival wound healing in non-epileptic patients receiving diphenylhydantoin sodium. Exp Med Surg 1958; 16: 41-53.

[11]. Hasamnis A, Mohanty B, Muralikrishna, Patil S. Evaluation of wound healing effect of topical Phenytoin on excisional wound in albino rats. J Young Pharm 2010;2:59-62.

[12]. Shaw J, Hughes CM, Lagan KM, Stevenson MR, Irwin CR, Bell PM. The effect of topical Phen ytoin on healing in diabetic foot ulcers: a randomized control trial. Diabet Med 2011;28:1154-7.

[13]. Talas G, Brown RA, McGrouther DA. Role of phenytoin in wound healing-a wound pharmacology perspective. Biochem Pharmacol. 1999; 57: 1085-94.

[14]. Rhodes RS, Heyneman CA, Culbertson VL, Wilson SE, Phatak HM. Topical phenytoin treatment of stage II decubitus ulcers in the elderly. Ann Pharmacother 2001;35:675-81.

[15]. Simpson GM, Kunz E, Slafta J. Use of diphenylhydantoin in treatment of leg ulcers. N Y State J Med 1965;65:886-8.

[16]. Modaghegh S, Salehian B, Tavassoli M. Use of phenytoin in healing of war and non-war wounds. A pilot study of 25 cases. Int $J$ Dermatol 1989;28:347-50.

[17]. Lodha SC, Lohiya ML, Vyas MCR, Bhandari S, Goyal RR, Harsh MK. Role of phenytoin in healing large abscess cavities. Br J Surg 1991;78:105-8

[18]. Bansal NK, Mukul. Comparison of topical phenytoin with normal saline in thetreatment of chronic trophic ulcers in leprosy. Int $\mathbf{J}$ Dermatol 1993;32:210-3

[19]. Rhodes RS, Heyneman CA, Culbertson VL, Wilson SE, Phatak HM. Topical phenytoin treatment of stage II decubitus ulcers in the elderly. Ann Pharmacother. 2001;35:675-81. 
[20]. Muthukumarasamy MG, Sivakumar G, Manoharan G. Topical phenytoin in diabetic foot ulcers. Diabetes Care 1991;14:909-11.

[21]. Tauro LF, Shetty P, Dsouza NT, Mohammd S, Sucharitha S. A comparative study of efficacy of topical phenytoin vs conventional wound care in diabetic ulcers. Int J Mol Med Sci 2013;3:8-16.

[22]. El-Nahas M, Gawish H, Tashoby M, State O. The impact of topical Phenytoin on recalcitrant neuropathic diabetic foot ulceration. J Wound Care 2009;18:33-7.

[23]. Carneiro PM, Nyawawa ET. Topical phenytoin versus EUSOL in the treatment of non-malignant chronic leg ulcers. East Afr Med J 2003;80:124-9.

[24]. AA Hasamnis, BK Mohanty, Muralikrishna, and S Patil. Evaluation of wound healing effect of topical phenytoin on excisional wound in Albino rats. J Young Pharm. 2010; 2(1): 59-62.

[25]. Shaw J, Hughes CM, Lagan KM, Stevenson MR, Irwin CR, Bell PM. The effect of topical phenytoin on healing in diabetic foot ulcers: a randomized controlled trial. Diabet Med. 2011; 28(10):1154-7.

[26]. Pai M, Sitaraman N, Kotian MS. Topical Phenytoin in diabetic ulcers: a double blind controlled trial. Indian J Med Sci 2001;55:593-9. 